\title{
Surface-Level Diversity and Decision-Making in Groups: When Does Deep-Level Similarity Help?
}

\author{
Katherine W. Phillips \\ Northwestern University \\ Gregory B. Northcraft \\ University of Illinois, Urbana-Champaign
}

Margaret A. Neale

Stanford University

\begin{abstract}
We examined how surface-level diversity (based on race) and deep-level similarities influenced three-person decision-making groups on a hidden-profile task. Surface-level homogeneous groups perceived their information to be less unique and spent less time on the task than surface-level diverse groups. When the groups were given the opportunity to learn about their deep-level similarities prior to the task, group members felt more similar to one another and reported greater perceived attraction, but this was more true for surface-level homogeneous than surface-level diverse groups. Surface-level homogeneous groups performed slightly better after discovering deep-level similarities, but discovering deep-level similarities was not helpful for surface-level diverse groups, who otherwise outperformed surface-level homogeneous groups. We discuss the implications of this research for managing diversity in the workplace.
\end{abstract}

KEYWORDS diversity, information sharing task, similarity-attraction, social categorization

A PRIMARY reason organizations use groups is to garner the benefits of the unique knowledge and information that group members might bring to the table (e.g. Schneider \& Northcraft, 1999). For nearly twenty years the sharing and integration of unique information in small group discussions has been the subject of much experimental (e.g. Stasser \& Stewart, 1992; Stasser \& Titus, 1985, 1987; Stasser, Vaughan, \&
Stewart, 2000; Stewart \& Stasser, 1995; Winquist \& Larson, 1998; Wittenbaum, 2000) and some

\section{Author's note}

Address correspondence to Katherine W. Phillips, Kellogg School of Management, Northwestern University, 2001 Sheridan Road, Evanston, IL 60208-2001, USA

[email: kwp@kellogg.northwestern.edu] 
field research (e.g. Larson, Christensen, Abbott, \& Franz, 1996, 1998). Reflecting the reality that all individuals bring a unique constellation of perspectives and experiences to small group discussions, this research examines hidden profile decision situations in which suboptimal decisions are likely to be made if unique information is not shared and integrated into the group discussion (Stasser \& Titus, 1985; for reviews see Wittenbaum, Hollingshead, \& Botero, 2004; Wittenbaum \& Stasser, 1996). In such situations, organizations and teams that can create environments where members are willing to share and discuss unique information may gain considerable competitive advantage.

In this article, we seek to understand more about how surface-level (i.e. race/ethnicity) and deep-level (i.e. experiences, preferences, and values) diversity affects the ability of groups to benefit from their unique information. We move beyond the typical social categorization perspective on diversity and highlight a byproduct of the social categorization processassumptions of in-group similarity-which has been overlooked by many researchers in this tradition (cf. Williams \& O'Reilly, 1998). We extend the argument that surface-level diversity triggers expectations that informational differences may be present in groups, and legitimates the expression of unique information (Phillips, 2003; Phillips \& Loyd, 2006; Van Knippenberg, De Dreu, \& Homan, 2004; Van Knippenberg \& Haslam, 2003). Moreover, by highlighting deep-level similarities in an effort to increase levels of attraction and diminish social categorization effects, we argue that managers may undermine the benefits of having surfacelevel diversity present in groups that must share unique information for effective performance. We provide some empirical evidence, while integrating research on collective information sampling in groups with that on the effects of group diversity.

\section{Collective information sampling in groups}

Research on information sharing in groups has found that sharing and integrating unique (i.e. known by a single member) as opposed to commonly held (i.e. known to all members) information into group decisions is easier said than done (for reviews see Stasser, 1999; Wittenbaum \& Stasser, 1996; Wittenbaum et al., 2004). One reason why unique information is mentioned and repeated less than commonly held information is because group members generally assume that the information they possess is the same as that possessed by others (unless contrary information is available) (Stasser, Stewart, \& Wittenbaum, 1995). The assumption is that there is no unique information, and that unmentioned information is information that other group members have deemed not of sufficient importance to discuss. When unique information does arise in groups, individuals are likely to assume that because the information is not widely held among the group members, it is less important than commonly held information, and therefore may fail to repeat that unique information during discussion. Moreover, people may feel uncomfortable expressing and focusing on unique information, because it is often inconsistent with their perceived expectations that their information should be similar to that of other group members (Gruenfeld, Mannix, Williams, \& Neale, 1996; Phillips, Mannix, Neale, \& Gruenfeld, 2004). Sharing unique information also leads to a lack of social validation from others, causing individuals to feel less accepted than when they share commonly held information (Wittenbaum \& Bowman, 2004).

Despite the information sharing barriers in groups, the discussion of unique information has been shown to increase when group members have greater reason to believe that unique information is going to be present. For instance, when expertise is labeled, or if people are explicitly forewarned that unique information is present, groups are better able to share and integrate the unique information into the discussion (Franz \& Larson, 2002; Schittekatte \& Van Hiel, 1996; Stasser et al., 1995; Stewart \& Stasser, 1995). To this end, Postmes, Spears and Cihangir (2001) have shown that unique information is more likely to be shared when groups have developed a norm 
of criticality instead of consensus. In such critical norm groups, the sharing of unique information is consistent with the group norms and the same overvaluing of shared information is less likely to occur. Thus, for groups to use their unique information effectively, the sharing of such information has to be perceived as a legitimate part of the groups' norms and identity (Jetten, Postmes, \& McAuliffe, 2002; Postmes, Haslam, \& Swaab, 2005; Van Knippenberg et al., 2004).

We posit that surface-level diversity may also serve this legitimation purpose in groups by making it more acceptable to discuss and value unique information that must be shared for effective performance. Recent research has distinguished between diversity in surface-level characteristics, which are immediately salient in groups (like race and gender), versus diversity in deep-level characteristics (like attitudes, opinions, information, and values), which become known only over time through verbal and nonverbal communication (Harrison, Price, \& Bell, 1998; Harrison, Price, Gavin, \& Florey, 2002; Jackson, May, \& Whitney, 1995). We expect surface-level differences to serve as a signal to group members that unique information may be present, leading them to be more aware of and willing to share unique information with the group. This argument is consistent with recent research on composition beliefs, which has shown that individuals believe diverse groups are likely to outperform homogeneous ones when unique ideas are needed, whereas homogeneous groups are likely to outperform diverse ones when commonality of ideas is needed (van Knippenberg \& Haslam, 2003). Also see the work on the mechanical and organic solidarity discussed by Postmes et al. (2005) supporting the notion that multiple sources of identity simultaneously exist in groups.

Our argument is based on the fact that a primary consequence of categorization processes is that people assume that they hold more similar deep-level perspectives with individuals who share their surface-level characteristics than with people who do not, on topics both relevant and irrelevant to the salient surface-level distinction (e.g. Allen \& Wilder, 1975, 1979; Chen \& Kenrick, 2002; Diehl, 1988; Holtz \& Miller, 1985; Phillips, 2003; Phillips \& Loyd, 2006; Tajfel, 1969; Wilder, 1984). For instance, Allen and Wilder (1979) divided students into two groups, allegedly on the basis of their preferences for oil paintings, and found greater assumed deep-level similarity between self and similar others than between self and dissimilar others on opinions about art (category relevant) and politics (category irrelevant). Recent research by Phillips and Loyd (2006) found this same pattern of assumed deep-level similarity in decision-making settings when examining the relationship between salient task-relevant (e.g. functional background) (also see Phillips, 2003) and irrelevant (e.g. campus geography) social categories and task opinions.

Especially at the beginning of a group's existence, when surface-level characteristics are most salient (Harrison et al., 1998, 2002), individuals are likely to use the presence of these characteristics to predict who shares deep-level perspectives with whom. In surface-level homogeneous groups, group members are likely to assume that they all possess the same information about the task, whereas in surface-level diverse groups members are likely to expect there to be differences in information (Antonio et al., 2004; Phillips, 2003; Phillips \& Loyd, 2006; Phillips et al., 2004). Thus, surface-level diversity triggers expectations that deep-level diversity will be present in groups, and serves to legitimize the surfacing of unique information. Significantly, this legitimation of unique information may apply not only to those who are (surface-level) 'different' in the group, but also to group members who are similar to most others. Phillips and Loyd (2006) found that dissenting members of the social majority voiced themselves more persistently and confidently when there was diversity present than when there was not. They concluded that the mere presence of diversity encouraged those dissenting group members to voice their disparate perspective when they might otherwise have remained silent and conformed to the opinion of their in-group (e.g. Abrams, Wetherell, Cochrane, Hogg, \& Turner, 1990; Asch, 1952). 
For these reasons, surface-level homogeneous groups should be less aware of the unique information they possess. As such, over the course of the group discussion they will be less likely to discuss unique information about the task than will surface-level diverse groups. This will result in the surface-level homogenous groups spending less time discussing the task than their diverse counterparts. Moreover, spending less time discussing the task will further hinder the discovery of unique information (Larson et al., 1996, 1998) leading to a confirmation of the group members' expectations that they all have the same information. In contrast, in groups where members possess unique information, surface-level diverse groups are more likely to discover and discuss unique information than surface-level homogeneous groups. Surface-level diverse groups assume that unique information is more likely to be there, and the presence of informational differences will be more consistent with their expectations. Likewise, if group members are aware that they might possess unique information, they should be inclined to spend more time discussing the task in an effort to discover and integrate that information. Thus we hypothesize that,

Hypothesis 1: Surface-level homogeneous groups will be less aware of their unique information, and will spend less time discussing the task than will surface-level diverse groups.

\section{Highlighting deep-level similarities}

Although surface-level diversity may be beneficial to teams or work groups that must share unique information for effective performance, diversity researchers have often found that diversity has a negative impact on communication and cohesion, and promotes high levels of detrimental group conflict (Ely \& Thomas, 2001; Jackson, Joshi \& Erhardt, 2003; Jehn, Northcraft, \& Neale, 1999; Pelled, Eisenhardt, \& Xin, 1999; for extensive reviews see also Milliken \& Martins, 1996; Williams \& O’Reilly, 1998). Over the past ten years, diversity researchers have focused on how to minimize the detrimental effects of social categorization on workgroups, with some suggesting that increasing the level of perceived deep-level similarity among group members should help them feel more socially validated and accepted by the other members of the group (e.g. Gaertner et al., 2000). Some social categorization researchers have advocated this perspective, suggesting that interventions designed to minimize the salience of social categories and instead 'de-categorize' or 're-categorize' group members by highlighting the similarities that exist across seemingly different individuals can be beneficial to group functioning (e.g. Gaertner et al., 2000; Northcraft \& Martin, 1982). For instance, Northcraft and Martin (1982) argued that, '... the liking, acceptance, and perceived competence of tokens and solos can be enhanced by making salient their similarities to majority group members in background, attitudes, and interests' (p. 114). Further, in a study of corporate outside directors of Fortune/Forbes 500 companies, Westphal and Milton (2000) found that minority board members (categorized on the basis of their functional background, industry background, education, race, or gender) were more influential on their focal boards when they had direct or indirect social ties, often through their common experiences with (focal board) majority members on other corporate boards.

This perspective is built on the wellestablished body of findings that similarity attracts (Byrne, 1971). Individuals generally are more attracted to and feel more comfortable interacting with others whom they perceive to be similar. For both surface-level homogeneous and surface-level diverse groups, an intervention designed to help group members discover their deep-level similarities should lead to greater feelings of attraction. Learning that one shares deep-level similarities with a fellow group member should also promote recategorization, increasing the likelihood that out-group members (i.e. those who have surface-level dissimilarities from other group members) will actually be seen as part of the in-group (e.g. Gaertner, Mann, Murrell, \& Dovidio, 1989; Kramer \& Brewer, 1984). The potential negative effects of social categorization may, 
subsequently, be reduced. As a result, we suggest that:

Hypothesis 2A: Members of groups who learn about deep-level similarities should perceive greater attraction from other group members than those who do not learn about deep-level similarities.

However, recent research has suggested that increasing this perceived similarity and attraction among the group members may come at a cost to the group's ability to benefit from the surface-level differences we have discussed here (Hornsey \& Jetten, 2004; Jetten et al., 2002; Postmes et al., 2001; van Knippenberg et al., 2004). For instance, Postmes et al. (2002) found that a focus on agreement and commonalities created norms of consensus that in turn undermined the sharing of unique information in groups. The effectiveness of recategorization or promoting the perception of others as similar to oneself as a means to diminish the detrimental effects of surface-level diversity has also been called into question by researchers of self-verification (e.g. Polzer, Milton, \& Swann, 2002; Swann, Milton, \& Polzer, 2000). These researchers argue that promoting the perception (or recategorization) of all group members as similar, may also discourage individuals from thinking and acting in ways associated with their unique category memberships (Gaertner et al., 1989). Yet, it is precisely these unique ways of thinking and acting that constitute the potential positive contribution of a diverse workgroup (Polzer et al., 2002, p. 297). Thus, highlighting deep-level similarities (especially in surface-level diverse groups), while leading to greater feelings of attraction toward the other group members, may undermine the groups' awareness of and willingness to embrace unique information.

In sum, the process of highlighting deeplevel similarities may undermine the signaling effect of surface-level diversity that legitimates expressing and discussing unique information by all group members. In other words, learning about deep-level similarities in surface-level diverse groups may interfere with the legitimation of difference and disagreement that surface-level diversity promotes. For example, if a work group who thinks they are diverse based on the surface-level characteristic of race finds that they all share the same attitudes, feelings, and experiences about the organization, they may be reluctant to disagree with each other going forward with the task. They may feel that they really are not all that different from each other after all. Thus, for surface-level diverse groups, although the realization of deep-level similarities may increase attraction toward the group, it may simultaneously increase pressures to conform to the group and undermine the discussion of unique information (Abrams et al., 1990).

For surface-level homogeneous groups highlighting similarities will also increase attraction, and may further interfere with the sharing of unique information since doing so poses a threat to feelings of acceptance and validation (Wittenbaum \& Bowman, 2004; Wittenbaum, Hubbell, \& Zuckerman, 1999). Thus, we believe that for surface-level homogeneous groups there will be somewhat of a 'floor' effect-the lack of surface-level differences will hinder the expectation of informational differences and the discussion of unique information, and then the highlighting of deep-level similarities will further hinder this process. Thus, we hypothesize that:

Hypothesis 2B: Highlighting deep-level similarities will lead to less awareness of unique information and less discussion time.

Hypothesis 2C: The effect of highlighting deep-level similarities on awareness of unique information and discussion time will be more pronounced for surface-level diverse groups than for surface-level homogeneous groups.

In terms of group performance, highlighting deep-level similarities should be detrimental because it undermines the legitimacy of discussing needed unique information. Although attraction may increase in groups as a result of learning about deep-level similarities, these deep-level similarities will be inconsistent with any expectation of unique information being present and thus are likely to hurt group performance, especially for surface-level diverse groups (e.g. Watson, Kumar, \& Michaelsen, 1993). As such, we would argue that: 
Hypothesis 3A: Surface-level diverse groups will outperform surface-level homogeneous groups.

Hypothesis 3B: Groups that highlight deep-level similarities will perform worse than groups that do not.

Hypothesis 3C: The performance of surface-level diverse groups that highlight deep-level similarities will be more negatively affected than the performance of surface-level homogeneous groups that highlight deep-level similarities.

To test the hypotheses, groups received an intervention asking them to discover deep-level similarities among group members. Exploring the effects of this intervention should allow for a better understanding of how different groups (i.e. those that are surface-level diverse or homogeneous) are affected by finding that they have deep-level similarities prior to engaging in a task where unique information must be shared.

\section{Method}

\section{Participants and overview}

A total of 216 undergraduate business students at a midwestern business school participated in this research. The median age of the participants was 21 years, and approximately $42 \%$ of the sample was female. The students participated in a class exercise designed to provide insight into group decision-making. Participants were given extra course credit for their participation, and a few of the best performing groups on the prediscussion task were randomly selected and entered into a raffle to receive certificates for free meals at local restaurants.

Participants first made individual assessments about who they believed committed a murder (see Stasser \& Stewart, 1992 for materials) based on the investigating detective's reports, and then discussed the case in three-person groups. Groups were either all male (42) or all female (30); the gender composition of the group is included as a covariate in all analyses presented. Eighty-two percent of the participants were white, $14 \%$ Asian, and the remainder African American or Hispanic. We used a 2 (surface-level homogeneous vs. surface-level diverse) $\times 2$ (deep-level similarities highlighted vs. control) between-subjects design and all analyses were conducted at the group level. There were a total of 31 surface-level homogeneous (i.e. three Caucasian group members) and 41 surface-level diverse groups (i.e. two Caucasian and one Asian, African American, or Hispanic). Forty groups were in the deep-level similarities condition and 32 were in the control condition. Participants were thoroughly debriefed about the purpose of the study after participation.

\section{Materials}

Every participant was given a packet of evidence from an apparent homicide investigation. The evidence consisted of interviews and a variety of supporting materials, including a list of suspects, a map, a personal note, and a newspaper article. All of these materials were adapted from Stasser and Stewart's (1992) study. Within each group, every member received the list of suspects, transcripts of initial interviews with each of the four key suspects, the newspaper article, and maps of the crime scene and surrounding area. The materials contained 42 clues in all, 12 of which were critical for solving the case. All participants received 30 commonly shared clues; 12 critical clues were distributed among the three group members such that each group member held some unique information pertinent to identifying the guilty suspect. These clues were embedded in followup interviews with the key suspects, and interviews with some additional witnesses. In all of the groups, a hidden profile existed because the best solution was more likely to be found if the unique information represented by the 12 unshared critical clues was shared.

\section{Procedure}

When participants arrived at the laboratory or in the classroom, they were randomly assigned to three-person groups based on their visible racial characteristics, with the constraint that all three members had to be of the same gender. In some groups the three group members appeared to all be Caucasian (surface-level homogeneous groups), and in other groups two of the members appeared Caucasian and 
one was of a different race (Asian, African American, or Hispanic). At the end of participation, group members provided their selfidentified race on the post-task questionnaire, and the experimenters' group assignments were validated against the information provided by the students.

During the study, participants were first given approximately 20 minutes to read and review materials in order to determine which of four suspects committed a murder (materials drawn from Stasser \& Stewart, 1992 and also used by Gruenfeld et al., 1996; Liljenquist, Galinsky, \& Kray, 2004; Phillips et al., 2004). Individuals were instructed to take notes on the case while reading the materials, because they would not be allowed to keep the case materials during the group discussion portion of the exercise. Participants made an individual assessment of who they believed was more likely to have committed the murder. They were asked to indicate how confident they were that each of the four suspects did or did not commit the murder. Subjects were also asked to provide a brief, written justification for their decision.

Participants were then gathered into their assigned three-person groups, and were instructed that they had 5 minutes to complete a short exercise before beginning group discussion. Groups were separated so that they could not overhear the deliberations of other groups. Half of the groups were randomly assigned to identify their similarities with the following instructions:

Working together with the other two members of your group, you have 5 minutes to discover as many things as possible that the three of you have in common. You may include anything that you have in common: friends, experiences, hobbies, books or movies that you liked, places to which you have all traveled, places where you all have lived or visitedanything that the three of you have in common. Put as many items on your list as possible.

The control groups were given the following instructions:

Working by yourself, you have 5 minutes to list as many US states and their capitals as you can remember. Put as many states and their capitals on your list as possible.
Control group members did not work together on the state capitals task in order to prevent the inadvertent sharing of similarity information while working together on the task. (A followup data collection revealed that working together to identify similarities increased group members' perceptions of similarity while working together on the state capitals task did not). ${ }^{1}$ In both conditions, participants were informed that the group during that session that generated the longest list (of similarities or state capitals) could receive a prize (certificates for free meals at a local restaurant).

After completing the 5-minute task, group members individually completed a 20-item survey titled 'Personal Assessment Inventory', by circling the number that best indicated how much they agreed with each of the statements on a scale from $1=$ strongly disagree to $7=$ strongly agree. 54 groups completed the survey. Embedded in the items were questions assessing how similar group members felt to one another and how attracted they thought the group would be to them (adapted from Eagly, 1967).

Once the short exercise and questionnaire were completed, participants were instructed to come to a group decision regarding which suspect they believed was most likely to have committed the murder. They were informed that they would have to report their group decision in exactly the same way that they had reported their individual decisions. Groups were given up to 35 minutes to complete their discussions, which were timed by the experimenter. Finally, upon completion of the group discussion, participants filled out an individual post-task questionnaire where they recorded the group decision in terms of how confident they were that each of the four possible suspects committed the murder. All participants then answered several questions assessing their group's task performance and management of information, as well as reporting their individual demographic characteristics.

Group task performance was operationalized as how confident the group was that the correct (guilty) suspect committed the murder. For instance, groups could report that they were 
$0 \%$ to $100 \%$ certain that the correct suspect committed the murder. Group members responded individually, and individual responses were aggregated to the group level as in most groups the individual responses were exactly the same (one way analysis of variance (ANOVA) for group membership $(F(71,143)=$ 9.35, intraclass correlation coefficient (ICC(1)) $=.74$ ). To illustrate that our results are indeed a reflection of group accuracy on this task, and not just higher levels of overall confidence in the groups' assessments, we also examined how confident groups were that each of the other three (innocent) suspects committed the murder.

\section{Dependent variables}

To measure group members' awareness about whether they possessed unique information, group members were asked to respond to the following item: 'The information in my packet was the same as that in others' packets', with 1 labeled 'not at all the same' and 7 labeled 'exactly the same' (Gruenfeld et al., 1996; Phillips et al., 2004). Group discussion time was measured in minutes and seconds with an average of 20.11 minutes $(S D=6.67)$. Likewise, perceptions of similarity were measured on the post-manipulation questionnaire with the following item 'I feel similar to the other members of my group'. How attracted group members thought others were to them was captured by four items measured on a 7-point Likert scale; 'I think I will like being a member of this group', 'I think the others in the group will like me', 'I am fun to be with', and 'I am easy to like' $(\alpha=.87)$. The questions were asked from the perspective of the participant because the internal feelings of the individual, even if others in the group were actually more or less attracted, were thought to be the critical assessment leading to how socially validated group members would feel during the group discussion.

To examine the number and content of the similarities listed by groups, two independent raters who were blind to the hypotheses first counted the number of similarities listed by each group. They then categorized the deep- level similarities listed into two categories: characteristics that were more obvious because of the nature of the groups and participants being used, versus less obvious characteristics that took more discussion and interaction to learn.

Obvious characteristics were things that were clear to all of the group members and potentially similar among many participants in the study, such as 'all members had been in (a major building on campus)', that all students must enter for class registration and other activities. Other similarities characterized as obvious included items such as group members were all wearing shoes; group members all have hair, etc. Less obvious characteristics were described as those that could not be discerned by the group members from simply looking at the group members or knowing that they were students at the university, i.e. similarities that could not have been a matter of common knowledge. These less obvious similarities between group members included personal likes and dislikes (such as all members liked certain foods or certain restaurants), similarities in places that individuals had visited, and similarities in nonobvious demographic characteristics (such as the number of siblings). Thus, group members had to be explicit in divulging nonobvious information about themselves to discover hidden interpersonal similarities.

The two raters were trained together on about $10 \%$ of the groups (eight groups). The 162 similarities listed in those eight groups were coded in the same category $93.2 \%$ of the time. This gave us confidence to allow the two coders to proceed independently with coding the rest of the groups. One coder independently coded 39 of the 72 groups and the other coder did the 25 remaining groups.

\section{Results}

To test our hypotheses regarding the impact of highlighting deep-level similarities in surfacelevel homogeneous and diverse groups, we used a 2 (surface-level homogeneous or surface-level diverse) $\times 2$ (deep-level similarity intervention or control) analysis of covariance 
(ANCOVA) approach to analyze the data. Gender composition of the group (male or female) was a covariate in the analyses.

All analyses were conducted at the group level. We tested the validity of aggregating the dependent variables of perceived uniqueness of information, feelings of similarity, and perceived attraction to the group level in two steps (see Bliese, 2000). First, we ran a one-way analysis of variance with group membership as the independent variable to ensure that the variance between teams was greater than the variance within teams. In all cases, the ANOVAs were significant $(F(71,143)=2.15, p<.001$; $F(53,108)=1.50, p<.04 ; F(53,108)=1.57$, $p<.03)$. We then calculated ICC(1) values for each of the dependent variables to test how much variability in individual responses was due to group membership (Bliese, 2000; Klein \& Kozlowski, 2000). The ICC(1) values were 0.28 , 0.15 , and 0.16 respectively, suggesting that there was significant interdependence in individual responses and that group membership accounted for a reasonable proportion of variance in individual responses on these three dependent variables (Bliese, 2000; James, 1982). ${ }^{2}$

\section{Manipulation checks}

The composition of the groups was validated against the self-reported race of each of the participants. This revealed that there were two groups initially categorized by the experimenter as racially homogeneous that self-identified as racially diverse. These groups were moved to the appropriate category before analysis.

To check on the outcomes of the similaritymanipulation, we first examined the number of similarities listed by surface-level homogeneous and diverse groups. We found no significant differences in the number of similarities listed by the two types of groups $(M=18.84, S D=$ 7.98). Likewise, there were no significant differences in the types of similarities listed by the groups with an average of $59 \%(S D=18 \%)$ being categorized as nonobvious by the coders. These results suggest that surface-level homogeneous and surface-level diverse groups naturally generated approximately the same number and type of similarities during the similarity intervention.

We also examined how similar group members felt to one another right after completing the manipulation, but before beginning discussion of the task. As expected, group members felt more similar to one another after highlighting deep level similarities $(M=4.71$, $S D=0.80)$ than in the control conditions $(M=$ $4.49, S D=0.76) \quad(F(1,49)=3.92, p=.05)$. Notably, there was a marginally significant interaction effect $(F(1,49)=2.86, p=.097)$, suggesting that deep-level similarities increased feelings of similarity more for surface-level homogeneous groups than for surface-level diverse groups (see Table 2 for means).

\section{Hypotheses tests}

In Hypothesis 1, we predicted that surface-level homogeneous groups would report discovering less unique information and would discuss the task less than would surface-level diverse groups. We conducted a multivariate analysis of variance analysis and found support for our hypothesis $(F(2,63)=3.14, p<.05)$. The followup univariate tests revealed that surface-level homogeneous groups reported that the information in their packets was more similar $(M=$ 3.31, $S D=1.18)$ than did surface-level diverse groups $(M=2.78, S D=0.80)(F(1,67)=4.39$, $p<.05)$. Likewise, we found that surface-level homogeneous groups $(M=17.90, S D=7.54)$ spent less time discussing the task than surfacelevel diverse groups $(M=21.72, S D=5.52)(F(1$, $64)=5.29, p<.03)$. Table 1 , which includes the correlations among all of the variables reported here, shows that discussion time and awareness of unique information were significantly correlated at $r=-.46, p<.01$. Controlling for the effects of discussion time on the awareness of unique information, the effect of surface-level group composition on awareness of unique information was no longer significant $(F<1.0$, $p>.30)$, suggesting that discussion time mediated the effects of surface-level composition on the discovery of unique information.

Hypothesis 2A predicted that learning about nontask relevant deep-level similarities would increase perceived attraction among the group. 
Table 1. Means, standard deviations, and correlations for study variables $(N=72)$

\begin{tabular}{lcccccccc}
\hline & Mean $(S D)$ & 1 & 2 & 3 & 4 & 5 & 6 & 7 \\
\hline 1. Surface-level composition & $0.43(0.50)$ & 1 & & & & & & \\
2. Deep-level similarity intervention & $0.56(0.50)$ & -.13 & 1 & & & & & \\
3. Awareness of unique information & $3.01(1.01)$ & $0.26^{*}$ & $-.21 \dagger$ & 1 & & & & \\
4. Time discussing task & $20.11(6.67)$ & $-.28^{*}$ & 0.11 & $-.46^{* *}$ & 1 & & & \\
5. Feelings of similarity & $4.62(0.78)$ & 0.17 & 0.14 & 0.02 & $-.29 *$ & 1 & & \\
6. Perceived attraction & $5.45(.54)$ & 0.02 & 0.13 & -.06 & -.02 & $0.53^{* *}$ & 1 & \\
7. Group performance & $61.81(29.20)$ & -.15 & 0.07 & $-.36^{* *}$ & $0.26^{*}$ & -.11 & -.05 & 1 \\
\hline
\end{tabular}

$\dagger p<.10 ; * p<.05 ; * * p<.01$.

Notes: $N=69$ for time discussing task and $N=54$ for the perceptions of similarity attraction.

Surface-level composition is coded 1 = homogeneous, $0=$ diverse; deep-level similarity intervention is coded $1=$ yes, $0=$ control; and awareness of unique information is coded $1=$ information is not the same (i.e. unique) to $7=$ information is the same.

Analysis revealed a marginally significant main effect for the similarity manipulation $(F(1,49)$ $=3.00, p<.10)$; groups exposed to the similarity intervention reported greater feelings of attraction $(M=5.29, S D=0.54)$ than those in the control condition $(M=5.15, S D=0.54)$. This main effect was accompanied by a significant and unexpected interaction effect $(F(1,49)=$ $5.38, p<.03)$. While surface-level homogeneous groups were more attracted to one another after the deep-level similarity manipulation, this was not the case for surface-level diverse groups (see Table 2 for means). Neither Hypotheses 2B (that there would be a main effect of the deeplevel similarity manipulation on awareness of unique information and discussion time) nor Hypothesis 2C (that the impact of surface-level composition would interact with the similarity intervention to affect awareness of unique information and discussion time) was supported $(F \mathrm{~s}<1, p \mathrm{~s}=n s)$.

Group performance was analyzed using an ANCOVA analysis with two covariates-gender composition and the average individual confidence about the a priori correct suspect prior to group discussion. Although the means were in the expected direction $(M=65.60, S D=$ 26.76 and $M=56.77, S D=31.91$ for surfacelevel diverse and homogeneous groups respectively), the main effects for surface-level diversity and the deep-level similarity manipulation were not supported $(F \mathrm{~s}<1, p \mathrm{~s}=n s)$. Further analysis did reveal a significant inter- action between surface-level diversity and the deep-level similarity intervention $(F(1,66)=$ $6.29, p<.02)$. As predicted in Hypothesis $3 c$, we found that surface-level diverse groups performed worse after being exposed to the deeplevel similarity manipulation $(M=61.00, S D=$ 28.69) than when they were not $(M=72.79, S D$ $=22.41)(F(1,37)=4.20, p<.05)$. In contrast and contrary to our expectations, surface-level homogeneous groups seemed to perform better after experiencing the similarity intervention $(M=67.89, S D=31.68)$ than when they did not $(M=46.35, S D=29.33)$, although this difference did not reach significance $(F(1,27)$ $=2.34, p=.138)$. (Both individual decisions and gender composition were controlled for in these follow-up analyses.) Additional analyses on how confident groups were that each of the three incorrect suspects committed the murder revealed no significant effects. This rules out the possibility that some conditions just made groups more confident than others did.

Finally, Table 1 includes correlations of all variables reported in the results. Of note, the correlations show that group composition was related to how long groups discussed the task $(r=-.28, p<.02)$, such that surface-level homogeneous groups discussed the task for a shorter period of time; and group discussion time was positively related to group performance-the group's confidence that the correct suspect committed the murder $(r=.26, p<.04)$. Moreover, group discussion time, awareness of 
Phillips et al. DIVERSITy AND PERFORMANCE

Table 2. Means (standard deviations) for feelings of similarity and attraction $(N=54$ groups)

\begin{tabular}{|c|c|c|c|c|}
\hline & $\begin{array}{c}\text { Surface-level } \\
\text { homogeneous } / \\
\text { Control }\end{array}$ & $\begin{array}{c}\text { Surface-level } \\
\text { homogeneous/ } \\
\text { Deep-level } \\
\text { similarity } \\
\text { intervention }\end{array}$ & $\begin{array}{c}\text { Surface-level } \\
\text { diverse/Control }\end{array}$ & $\begin{array}{c}\text { Surface-level } \\
\text { diverse/ } \\
\text { Deep-level } \\
\text { similarity } \\
\text { intervention }\end{array}$ \\
\hline Feelings of similarity & $4.41(0.88)_{\mathrm{a}}$ & $5.14(0.69)_{\mathrm{ab}}$ & $4.60(0.60)$ & $4.44(0.75)_{\mathrm{b}}$ \\
\hline Perceived attraction & $5.00(0.54)_{\mathrm{a}}$ & $5.56(0.49)_{\mathrm{ab}}$ & $5.34(0.51)$ & $5.12(0.51)_{\mathrm{b}}$ \\
\hline
\end{tabular}

Note: Means sharing subscripts within each row differ from one another significantly at $p<.05$.

unique information, and group performance were all significantly correlated $(r \mathrm{~s}>.26, p \mathrm{~s}<$ $.05)$, meaning that groups performed better when they spent more time in discussion and, in turn, became more aware of the differences in information present among group members.

\section{Discussion}

This article reports how different types of diversity-surface- and deep-level-influence group decision-making and performance. Understanding the impact of diversity on decisionmaking groups is often complicated by the different sources of diversity that can exist and the assumed correlation among these sources. In this study, we moved beyond the typical social categorization perspective on diversity by highlighting a by-product of the social categorization process-assumptions of ingroup similarity-which has been overlooked by researchers in this tradition. We argue that surface-level diversity triggers expectations that informational differences may be present in groups, making it more expected and legitimate for group members to raise and discuss unique information that may be critical for group performance. Moreover, by highlighting deep-level similarities in an effort to increase levels of attraction and diminish social categorization effects, managers may undermine the benefits of having surface-level diversity present in groups that must share unique information for effective performance.

While our results revealed a substantial amount of support for this perspective, there were some surprises. First, in support of this perspective we found that surface-level diverse groups perceived their information to be less similar, and spent more time discussing the task than did surface-level homogeneous groups. Moreover, the more time group members spent discussing the task, the more likely they were to perceive the information as different. These results were strong, expected, and independent of whether groups learned about deep-level similarities.

As argued and shown by past research, learning about deep-level similarities had a positive impact on how similar and how attracted group members felt toward one another (Byrne, 1971), but mostly for the surface-level homogeneous groups. The similarity manipulation did not reliably increase perceived attraction for the surface-level diverse groups, even though our manipulation check revealed that the number and type of similarities generated by the two types of groups did not differ. Moreover, we did not find evidence that the deep-level similarities had a differential impact on surface-level homogeneous and diverse groups' awareness of unique information or discussion time. There was only the significant interaction on group performance showing that surface-level diverse groups performed worse after being exposed to the deep-level similarity manipulation. In contrast, surface-level homogeneous groups seemed to be helped by the intervention, although not significantly so. Overall, the general arguments made in this article were supported with some exceptions. A closer look at the deep-level similarity manipulation may lend some insight into future research opportunities. 
Group members were instructed to spend five minutes discovering as many things as possible that all three of the group members had in common. This meant that in the process of finding these similarities, groups were also likely to discover similarities that bonded only subsets of the members, and differences where none of the group members were similar. Without a measure of these partially shared similarities or the differences that surfaced, it is difficult to determine exactly how they might have affected our results here. However, given that all groups had the same amount of time for the exercise and that there were no differences in the number of similarities discovered, it is likely that there were no systematic differences across the conditions on the number of differences found either. Future research should disentangle the effects of highlighting similarities from the effects of discovering differences, and the implications of doing this in light of a group's surface-level composition.

Sharing unique information is difficult in groups, because sharing the information often means that one has to disagree with the rest of the group about what is important for making the group decision. Providing the context that allows groups to benefit fully from the unique information and perspectives that each group member holds is a difficult task. This research suggests that surface-level diversity might be beneficial for groups because of the legitimacy it lends to sharing unique perspectives. For surface-level homogeneous groups the obvious similarities among group members hindered the recognition of unique information and led them to perform worse. In fact, the surfacelevel homogeneous groups in the control condition performed worse than any others in our sample. For these groups, sharing unique information may be particularly difficult because of the social risks involved (e.g. Gruenfeld et al., 1996; Wittenbaum et al., 1999).

Surface-level homogeneous groups, where group members are concerned about being accepted by their fellow in-group members, suffer more from conformity pressures that prevent them from sharing unique information and opinions than do surface-level diverse groups (e.g. Abrams et al., 1990; Janis, 1982; Phillips \& Loyd, 2006). Postmes et al. (2001) suggest that one way to overcome the reluctance to share unique information is to develop norms of criticality instead of consensus. This may be even more important for surface-level homogeneous than for surface-level diverse groups. Moreover, homogeneity without feelings of attraction and acceptance may be detrimental to groups when sharing unique information is crucial for performance (Gruenfeld et al., 1996; Jehn \& Shah, 1997). There is a fine line that surface-level homogeneous groups need to walk. Feeling too similar to one another may undermine the amount of time group members spend on the task, as suggested by the correlation found here between feelings of similarity and discussion time, but not feeling similar enough may lead group members to feel insecure and have concern about sharing unique information at all.

Future research should attempt to disentangle the effects of similarity and familiarity on work teams. For instance, does familiarity have the same effect on surface-level homogeneous as it does on diverse groups? How familiar do people need to be with one another before the potential benefits of familiarity outweigh the potential downsides of similarity/diversity? From the study conducted here, it seems that increasing familiarity (e.g. via 5 minutes of discussing similarities) can only slightly overcome the conformity pressures that come along with surface-level homogeneity. However, it may take considerably longer for surface-level diverse groups to benefit from familiarity (Watson et al., 1993). The amount of diversity present in our groups, and the small group size, may also be limitations that should be considered in future research. Would the diverse groups have performed even better if they had had greater surface-level diversity? Would the results be the same if a different type of surface-level diversity were used?

In conclusion, as organizations attempt to cope with the changing demography of the work force there is a natural tendency to believe that what enhances the performance of surfacelevel homogeneous groups may also enhance 
the performance of surface-level diverse groups. The current research suggests that enhancing the performance of workgroups is more complex than that. Our research found that attempting to diminish the salience of potentially disruptive categorical boundaries by asking members of racially diverse groups to focus on their similarities was detrimental for group performance. Diversity can be beneficial for groups, not merely because individuals belonging to different subgroups are likely to have access to differing information, but also because the presence of salient differences may legitimate the introduction and consideration of unique information in the group's decisionmaking process. Both the positive and negative effects of surface-level and deep-level diversity in the workplace are yet to be fully understood. This work is another step toward understanding the effects of diversity on groups where sharing unique information is crucial to performance.

\section{Notes}

1. We conducted a follow-up study with 12 three-person racially homogeneous groups that either worked together to identify US states and capitals or worked together to identify similarities. Results revealed that identifying similarities does indeed lead individuals to feel more similar to one another than just working together recalling US states and capitals $(F(1,10)=10.48, p<.01)$. Moreover, a comparison of feelings of similarity by the groups that worked together to identify US states and capitals $(M=4.71, S D=.56)$ and those that worked separately when they identified states and capitals (from the initial study) $(M=4.41, S D$ $=.88$ ) revealed that there was no significant difference between the two types of groups $(t(18)=.821, p=.423)$. Theoretically, we do not believe that just working together (without discussing similarities) could generate our same pattern of data. The highlighting of similarities in surface-level diverse groups causes a particular threat to expectations that just working together would not. For instance, in the work by Gruenfeld et al. (1996) familiarity was found to lead to better performance when unique information needed to be shared. This suggests that both the surface-level homogeneous and diverse groups should have improved their performance after working together to highlight deep-level similarities if simply working together is all that is important. As this was not the case we believe that our current manipulation of highlighting similarities does indeed add a unique contribution to people's experience, beyond just working together.

2. Bliese (2000, p. 361) reports that values between .05 and .30 should be expected in most applied field settings.

\section{Acknowledgments}

The authors are indebted to the graduate students who assisted in the data collection efforts. Also, we thank KTAG for financial support and the members of the Social Interactions Lab at Northwestern University for their helpful comments. We thank Elson Huang and Tanya Canak for coding help. In addition, I would like to thank the audiences at several colloquiums who offered their insights on this work.

\section{References}

Abrams, D. M., Wetherell, M., Cochrane, S., Hogg, M. A., \& Turner, J. C. (1990). Knowing what to think by knowing who you are: Self-categorization and the nature of norm formation, conformity and group polarization. British Journal of Social Psychology, 29, 97-119.

Allen, V. L., \& Wilder, D. A. (1975). Categorization, beliefs similarity, and intergroup discrimination. Journal of Personality and Social Psychology, 32, 971-977.

Allen, V. L., \& Wilder, D. A. (1979). Group categorization and attribution of belief similarity. Small Group Behavior, 10, 73-80.

Antonio, A. L., Chang, M. J., Hakuta, K., Kenny, D. A., Levin, S., \& Milem, J. F. (2004). Effects of racial diversity on complex thinking in college students. Psychological Science, 15, 507-510.

Asch, S. E. (1952). Social psychology. Englewood Cliffs, NJ: Prentice-Hall.

Bliese, P. D. (2000). Within-group agreement, non-independence, and reliability: Implication for data aggregation and analysis. In K. J. Klein \& S. W. J. Kozlowski (Eds.), Multilevel theory, research, and methods in organizations: Foundations, extensions, and new directions (pp. 349-381). San Francisco: Jossey-Bass.

Byrne, D. (1971). The attraction paradigm. New York: Academic Press. 
Chen, F. F., \& Kenrick, D. T. (2002). Repulsion or attraction? Group membership and assumed attitude similarity. Journal of Personality and Social Psychology, 83, 111-125.

Diehl, M. (1988). Social identity and minimal groups: The effects of interpersonal and intergroup attitudinal similarity on intergroup discrimination. British Journal of Social Psychology, 27, 289-300.

Eagly, A. H. (1967). Involvement as a determinant of response to favorable and unfavorable information. Journal of Personality and Social Psychology, 7, 15.

Ely, R., \& Thomas, D. (2001). Cultural diversity at work: The effects of diversity perspectives on work group processes and outcomes. Administrative Science Quarterly, 46, 229-273.

Franz, T. M., \& Larson, J. R., Jr. (2002). The impact of experts on information sharing during group discussion. Small Group Research, 33, 383-411.

Gaertner, S., L., Dovidio, J. F., Banker, B. S., Houlette, M., Johnson, K. M., \& McGlynn, E. A. (2000). Reducing intergroup conflict: From superordinate goals to decategorization, recategorization, and mutual differentiation. Group Dynamics, 4, 98-114.

Gaertner, S. L., Mann, J., Murrell, A., \& Dovidio, J. (1989). Reducing intergroup bias: The benefits of recategorization. Journal of Personality and Social Psychology, 57, 239-249.

Gruenfeld, D. H., Mannix, E. A., Williams, K. Y., \& Neale, M. A. (1996). Group composition and decision making: How member familiarity and information distribution affect process and performance. Organizational Behavior and Human Decision Processes, 67, 1-15.

Harrison, D. A., Price, K. H., \& Bell, M. P. (1998). Beyond relational demography: Time and effects of surface- and deep-level diversity on work group cohesion. Academy of Management Journal, 41, 96-107.

Harrison, D. A., Price, K. H., Gavin, J. A., \& Florey, A. T. (2002). Time, teams, and task performance: Changing effects of surface- and deep-level diversity on group functioning. Academy of Management Journal, 45, 1029-1045.

Holtz, R., \& Miller, N. (1985). Assumed similarity and opinion certainty. Journal of Personality and Social Psychology, 48, 890-898.

Hornsey, M. J., \& Jetten, J. (2004). The individual within the group: Balancing the need to belong with the need to be different. Personality and Social Psychology Review, 8, 248-264.

Jackson, S. E., Joshi, A., \& Erhardt, N. L. (2003).
Recent research on team and organizational diversity: SWOT analysis and implications. Journal of Management, 29, 801-830.

Jackson, S. E., May, K. E., \& Whitney, K. (1995). Understanding the dynamics of diversity in decision-making teams. In R. A. Guzzo \& E. Salas (Eds.), Team decision-making effectiveness in organizations (pp. 204-261). San Francisco: Jossey-Bass.

James, L. R. (1982). Aggregation bias in estimates of perceptual agreement. Journal of Applied Psychology, 67, 219-229.

Janis, I. L. (1982). Victims of groupthink (2nd ed). Boston: Houghton Mifflin.

Jehn, K., Northcraft, G., \& Neale, M. (1999). Why differences make a difference: A field study of diversity, conflict, and performance in work groups. Administrative Science Quarterly, 44, $741-763$.

Jehn, K. A., \& Shah, P. P. (1997). Interpersonal relationships and task performance: An examination of mediation processes in friendship and acquaintance groups. Journal of Personality and Social Psychology, 72, 775-790.

Jetten, J., Postmes, T., \& McAuliffe, B. J. (2002).

'We're all individuals': Group norms of individualism and collectivism, levels of identification and identity threat. European Journal of Social Psychology, 32, 189-207.

Klein, K. J., \& Kozlowski, S. W. J. (2000). From micro to meso: Critical steps in conceptualizing and conducting multilevel research. Organizational Research Methods, 3, 211-236.

Kramer, R., \& Brewer, M. B. (1984). Effects of group identity on resource use in a simulated commons dilemma. Journal of Personality and Social Psychology, 46, 1044-1057.

Larson, J. R., Jr., Christensen, C., Abbott, A. S., \& Franz, T. M. (1996). Diagnosing groups: Charting the flow of information in medical decision-making teams. Journal of Personality and Social Psychology, 71, 315-330.

Larson, J. R., Jr., Christensen, C., Abbott, A. S., \& Franz, T. M. (1998). Diagnosing groups: The pooling, management, and impact of shared and unshared case information in team-based medical decision-making. Journal of Personality and Social Psychology, 75, 93-108.

Liljenquist, K. A., Galinsky, A. D., \& Kray, L. J. (2004). Exploring the rabbit hole of possibilities by myself or with my group: The benefits and liabilities of activating counterfactual mind-sets for information sharing and group coordination. Journal of Behavioral Decision Making, 17, 263-279. 
Milliken, F. J., \& Martins, L. L. (1996). Searching for common threads: Understanding the multiple effects of diversity in organizational groups. Academy of Management Review, 21, 402-433.

Northcraft, G. B., \& Martin, J. (1982). Double jeopardy: Resistance to affirmative action from potential beneficiaries. In B. Gutek (Ed.), Sex role stereotyping and affirmative action policy (pp. 81-130). Los Angeles, CA: Institute of Industrial Relations, UCLA.

Pelled, L. H., Eisenhardt, K. M., \& Xin, K. R. (1999). Exploring the black box: An analysis of work group diversity, conflict, and performance. Administrative Science Quarterly, 44, 1-28.

Phillips, K. W. (2003). The effects of categorically based expectations on minority influence: The importance of congruence. Personality and Social Psychology Bulletin, 29, 3-13.

Phillips, K. W., \& Loyd, D. L. (2006). When surface and deep-level diversity collide: The effects on dissenting group members. Organizational Behavior and Human Decision Processes, 99, 143-160.

Phillips, K. W., Mannix, E., Neale, M., \& Gruenfeld, D. (2004). Diverse groups and information sharing: The effects of congruent ties. Journal of Experimental Social Psychology, 40, 498-510.

Polzer, J. T., Milton, L. P., \& Swann, W. B. Jr. (2002). Capitalizing on diversity: Interpersonal congruence in small work groups. Administrative Science Quarterly, 47, 296-324.

Postmes, T., Haslam, A., \& Swaab, R. I. (2005). Social influence in small groups: An interactive model of social identity formation. European Review of Social Psychology, 16, 1-42.

Postmes, T., Spears, R., \& Cihangir, S. (2001). Quality of decision making and group norms. Journal of Personality and Social Psychology, 80, 918-930.

Schittekatte, M., \& Van Hiel, A. (1996). Effects of partially shared information and awareness of unshared information on information sampling. Small Group Research, 27, 431-449.

Schneider, S. K., \& Northcraft, G. B. (1999). Three social dilemmas of workforce diversity in organizations: A social identity perspective. Human Relations, 52, 1445-1467.

Stasser, G. (1999). The uncertain role of unshared information in collective choice. In L. L. Thompson, J. M. Levine, \& D. M. Messick (Eds.), Shared cognition in organizations: The management of knowledge (pp. 49-69). Hillsdale, NJ: Erlbaum.

Stasser, G., \& Stewart, D. (1992). Discovery of hidden profiles by decision-making groups: Solving a problem versus making a judgment. Journal of Personality and Social Psychology, 63, 426-434.

Stasser, G., Stewart, D. D., \& Wittenbaum, G. M. (1995). Expert roles and information exchange during discussion: The importance of knowing who knows what. Journal of Experimental Social Psychology, 31, 244-265.

Stasser, G., \& Titus, W. (1985). Pooling of unshared information in group decision making: Biased information sampling during discussion. Journal of Personality and Social Psychology, 48, 1467-1478.

Stasser, G., \& Titus, W. (1987). Effects of information load and percentage of shared information on the dissemination of unshared information during group discussion. Journal of Personality and Social Psychology, 53, 81-93.

Stasser, G., Vaughan, S. I., \& Stewart, D. D. (2000). Pooling unshared information: The benefits of knowing how access to information is distributed among group members. Organizational Behavior and Human Decision Processes, 82, 102-116.

Stewart, D. D., \& Stasser, G. (1995). Expert role assignment and information sampling during collective recall and decision-making. Journal of Personality and Social Psychology, 69, 619-628.

Swann, W. B., Jr., Milton, L. P., \& Polzer, J. T. (2000). Should we create a niche or fall in line? Identity negotiation and small group effectiveness. Journal of Personality and Social Psychology, 79, 238-250.

Tajfel, H. (1969). Cognitive aspects of prejudice. Journal of Social Issues, 25, 79-97.

Van Knippenberg, D., De Dreu, C. K. W., \& Homan, A. C. (2004). Work group diversity and group performance: An integrative model and research agenda. Journal of Applied Psychology, 89, 1008-1022.

Van Knippenberg, D., \& Haslam, S. A. (2003). Realizing the diversity dividend: Exploring the subtle interplay between identity, ideology and reality. In S. A. Haslam, D. van Knippenberg, M. Platow, \& N. Ellemers (Eds.), Social identity at work: Developing theory for organizational practice (pp. 61-77). New York: Taylor \& Francis.

Watson, W., Kumar, K., \& Michaelsen, L. (1993). Cultural diversity's impact on interaction process and performance: Comparing homogeneous and diverse task groups. Academy of Management Journal, 36, 590-602.

Westphal, J. D., \& Milton, L. P. (2000). How experience and network ties affect the influence of demographic minorities on corporate boards. Administrative Science Quarterly, 45, 366-398.

Wilder, D. A. (1984). Predictions of belief homogeneity and similarity following social 
categorization. British Journal of Social Psychology, 23, 323-333.

Williams, K., \& O'Reilly, C. (1998). Demography and diversity in organizations: A review of 40 years of research. In B. M. Staw \& R. Sutton (Eds.), Research in organizational behavior (Vol. 21, pp. 77-140). Greenwich, CT: JAI Press.

Winquist, J. R., \& Larson, J. R. (1998). Information pooling: When it impacts group decision making. Journal of Personality and Social Psychology, 74, 371-377.

Wittenbaum, G. M. (2000). The bias toward discussing shared information: Why are high status members immune? Communication Research, 27, 379-401.

Wittenbaum, G. M., \& Bowman, J. M. (2004). A social validation explanation for mutual enhancement. Journal of Experimental Social Psychology, 40, 169-184.

Wittenbaum, G. M., Hollingshead, A. B., \& Botero, I. C. (2004). From cooperative to motivated information sharing in groups: Moving beyond the hidden profile paradigm. Communication Monographs, 71, 286-310.

Wittenbaum, G. M., Hubbell, A. P., \& Zuckerman, C. (1999). Mutual enhancement: Toward an understanding of the collective preference for shared information. Journal of Personality and Social Psychology, 77, 967-978.

Wittenbaum, G. M., \& Stasser, G. (1996). Management of information in small groups. In J. L. Nye \& A. M. Brower (Eds.), What's social about social cognition? Research on socially shared cognition in small groups (pp. 3-28). Thousand Oaks, CA: Sage.

Paper received 8 November 2004; revised version accepted 28 February 2006.

\section{Biographical notes}

KATHERINE W. PHILLIPS is associate professor of management and organizations at the Kellogg School of Management at Northwestern University. Her research focuses on diversity in decision making groups, information sharing, minority influence, identity boundary management and the effects of status in groups. She received her PhD from the Graduate School of Business at Stanford University.

GREGORY B. NORTHCRAFT is the Harry J. Gray Professor of Executive Leadership in the department of business administration, and Institute of Labor and Industrial Relations, at the University of Illinois. His major research interests include conflict management and negotiation, collaboration in teams, managerial decision making, and employee motivation and job design, particularly in high-technology manufacturing settings. He received his PhD in social psychology at Stanford University.

Margaret A. NeAle is the John G. McCoy-Banc One Corporation Professor of Organizations and Dispute Resolution at the Graduate School of Business at Stanford University. Professor Neale's major research interests include bargaining and negotiation, distributed work groups, and team composition, learning, and performance. She received her $\mathrm{PhD}$ in business administration from the University of Texas. 